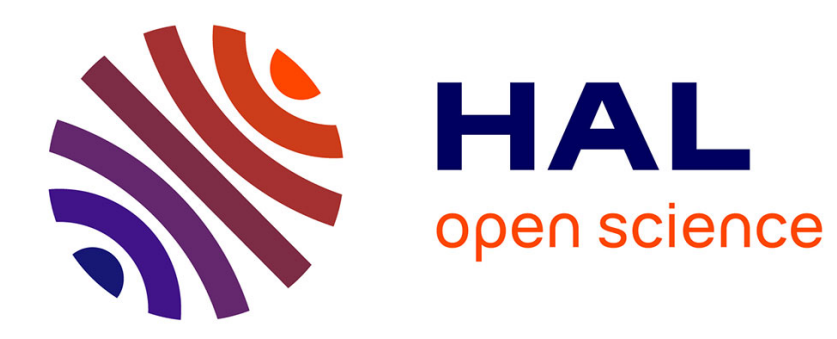

\title{
Solid films and transports in cellular foams
}

\author{
M. T. Hoang, Camille Perrot
}

\section{To cite this version:}

M. T. Hoang, Camille Perrot. Solid films and transports in cellular foams. Journal of Applied Physics, 2012, 112 (5), pp.054911-6. 10.1063/1.4751345 . hal-00731906

\section{HAL Id: hal-00731906 https://hal.science/hal-00731906}

Submitted on 17 Sep 2012

HAL is a multi-disciplinary open access archive for the deposit and dissemination of scientific research documents, whether they are published or not. The documents may come from teaching and research institutions in France or abroad, or from public or private research centers.
L'archive ouverte pluridisciplinaire HAL, est destinée au dépôt et à la diffusion de documents scientifiques de niveau recherche, publiés ou non, émanant des établissements d'enseignement et de recherche français ou étrangers, des laboratoires publics ou privés. 


\section{AIP Applied Physics}

\section{Solid films and transports in cellular foams}

Minh Tan Hoang and Camille Perrot

Citation: J. Appl. Phys. 112, 054911 (2012); doi: 10.1063/1.4751345

View online: http://dx.doi.org/10.1063/1.4751345

View Table of Contents: http://jap.aip.org/resource/1/JAPIAU/v112/i5

Published by the American Institute of Physics.

\section{Related Articles}

Spectral analysis of $\mathrm{x}$-ray emission created by intense laser irradiation of copper materials Rev. Sci. Instrum. 83, 10E114 (2012)

Experimental study of homogeneous nucleation from the bismuth supersaturated vapor: Evaluation of the surface tension of critical nucleus

J. Chem. Phys. 136, 224506 (2012)

Aggregation kinetics of detonation nanocarbon

Appl. Phys. Lett. 100, 214106 (2012)

Infrared spectroscopy and modeling of co-crystalline $\mathrm{CO} 2 \cdot \mathrm{C} 2 \mathrm{H} 2$ aerosol particles. I. The formation and decomposition of co-crystalline $\mathrm{CO} 2 \cdot \mathrm{C} 2 \mathrm{H} 2$ aerosol particles

J. Chem. Phys. 136, 094509 (2012)

Infrared spectroscopy and modeling of co-crystalline $\mathrm{CO} 2 \cdot \mathrm{C} 2 \mathrm{H} 2$ aerosol particles. II. The structure and shape of co-crystalline $\mathrm{CO} 2 \cdot \mathrm{C} 2 \mathrm{H} 2$ aerosol particles

J. Chem. Phys. 136, 094510 (2012)

\section{Additional information on J. Appl. Phys.}

Journal Homepage: http://jap.aip.org/

Journal Information: http://jap.aip.org/about/about_the_journal

Top downloads: http://jap.aip.org/features/most_downloaded

Information for Authors: http://jap.aip.org/authors

\section{ADVERTISEMENT}

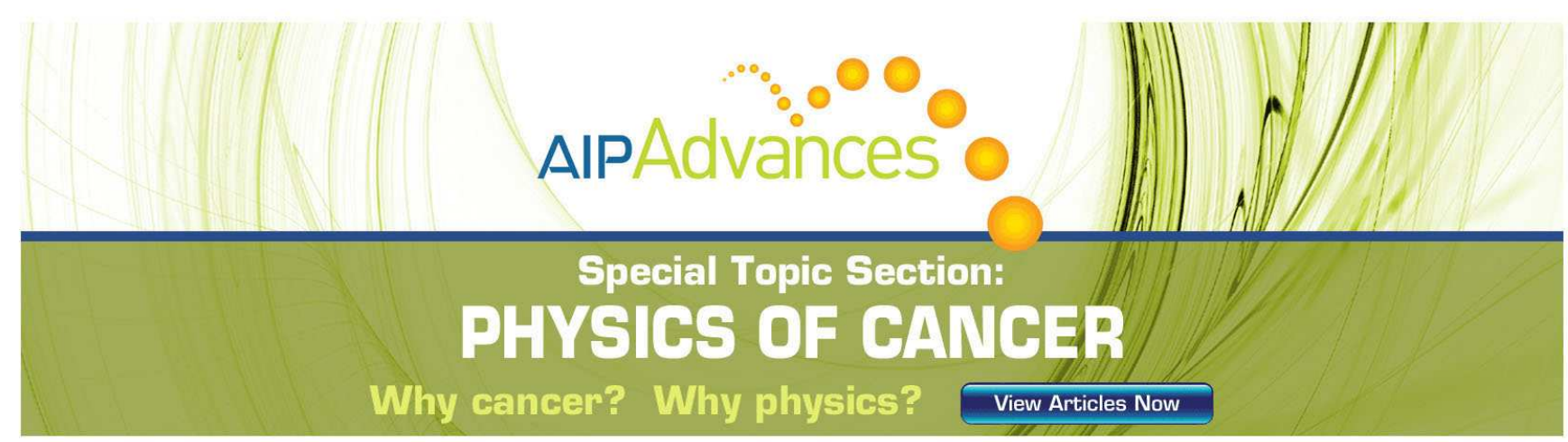




\title{
Solid films and transports in cellular foams
}

\author{
Minh Tan Hoang ${ }^{1,2}$ and Camille Perrot ${ }^{1, a)}$ \\ ${ }^{1}$ Université Paris-Est, Laboratoire Modélisation et Simulation Multi Echelle, MSME UMR 8208 CNRS, \\ 5 bd Descartes, 77454 Marne-la-Vallée, France \\ ${ }^{2}$ Faurecia Interior Systems, Acoustic TechCenter, Z. I. François Sommer BP 13, 08210 Mouzon, France
}

(Received 9 May 2012; accepted 9 August 2012; published online 12 September 2012)

\begin{abstract}
We show that critical path ideas lead to the identification of two local characteristic sizes for the long wavelength acoustic properties in cellular solids, the pore and throat sizes. Application of the model to real foam samples, which may contain solid films or membranes yields quantitative agreement between a finite-element numerical homogenization approach and experimental results. From three routinely available laboratory measurements: the open porosity $\phi$, the static viscous permeability $k_{0}$, and the average struts length $L_{m}$ obtained from microscopy analysis; asymptotic transport parameters at high-frequencies and the normal incidence sound absorption coefficient are derived with no adjustable parameters. (C) 2012 American Institute of Physics. [http://dx.doi.org/10.1063/1.4751345]
\end{abstract}

\section{INTRODUCTION}

Solid films or membranes in real porous media such as polyurethane or metallic foams only account for a very small fraction of material in the overall mass of the porous media. Yet, their role might be of primary importance in the understanding of transport and acoustical properties of these foams. As a long wavelength wave propagates, the viscoinertial and thermal interactions between the disordered interconnected pores and the surrounding air pose a fundamental physical challenge in the microstructural identification of features, which are characteristic of the overall transport phenomena. Part of the solution of this problem lies in the fact that the overall dissipation of the real porous media is expected to be dominated by a few key linkages ${ }^{1,2}$ responsible for the main energy dissipation mechanisms; and in the successful identification of the critical-path responsible for viscous ones. ${ }^{3}$ Here, we demonstrate that a complementary part of the solution involves the fluid-structure interaction between the (thermally conducting) air inside the interconnected pores and the membranes that partially close them. Using finite element analysis on a periodic unit-cell local geometry model, experimental estimations of transport parameters, and high resolution imaging of real foam samples, we characterize the closure rate of membranes at the junction between interconnected pores. We find that the presence of non-closed membranes between pores effectively corresponds to the introduction of a second set of critical characteristic sizes, which governs the inertial effects and meanwhile enables a correct description of the thermal ones. For an increasing rate of semi-open membranes, because of the fact that the throat size reduces, then the length $\Lambda$, which has been identified as a weighted volume-to-surface ratio for the porous medium diminishes, whereas the infinite tortuosity factor $\alpha_{\infty}$ increases as a result of strong cross section changes. ${ }^{4}$ An increasing membrane closure rate promotes the emergence of a stronger contrast between two distinctive

\footnotetext{
a) Author to whom correspondence should be addressed. Electronic mail: camille.perrot@univ-paris-est.fr.
}

critical characteristic sizes inside one periodic unit-cell, the size of a pore itself and the size of the interconnections between pores, which provides a scaling behavior of real polyurethane foam samples for both viscous and inertial effects. The presence of membranes also favors surface effects known to have a strong influence in transport phenomena such as diffusion controlled reactions. As characterized from the low frequency asymptotic behavior of thermal exchanges between the solid frame and the surrounding air measured in a standing wave tube, the trapping constants $\Gamma=1 / k_{0}^{\prime}$ of the real foam samples tend to agree well with the ones simulated from the previously identified visco-inertial scaling behavior of the unit-cells. A combination of advanced experiments and detailed numerical modeling of fluid-structure interactions at the pore scale reveals the basic microstructural features behind transport phenomena and shows quantitatively how these thin elements are crucial to the correct microstructural description of long-wavelengths acoustic waves' propagation and dissipation in real foam samples.

\section{MATERIALS AND METHOD}

A three-dimensional cellular solid or foam is an interconnected network of solid struts or plates forming the edges or faces of polyhedra, which pack to fill space. Foamed or cellular solids may be classified according to the type of cell structures: open-celled if the solid of which the foam is made is contained in the cell edges only, closed-cell if solid membranes close off the cell faces too. In many types of foams, this thin skin framed by thicker edges is partially open and partially closed. Carefully controlling the closure rate of membranes at the junction between interconnected pores allows for the fine tuning of foam transport and acoustical properties. When an acoustic wave propagates through an air saturated porous media having a motionless and isothermal skeleton, the frequency-dependent interplay between viscosity and inertia, and thermal conduction produce a spatial gradient of fluid velocity and temperature; and the shear combined with heat transfer between successive layers of fluid causes compression wave attenuation. ${ }^{5}$ The characteristic lengths of the compression waves 
a
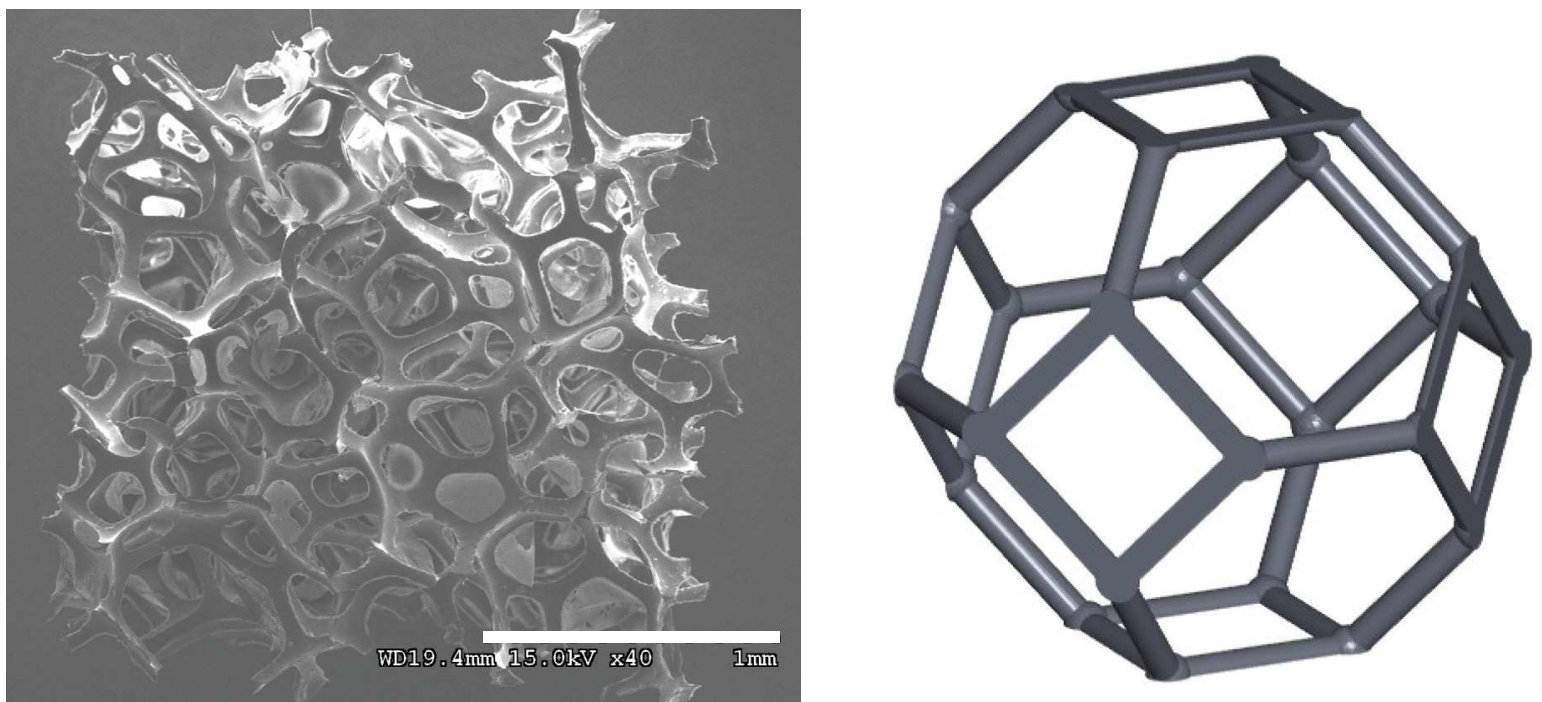

b
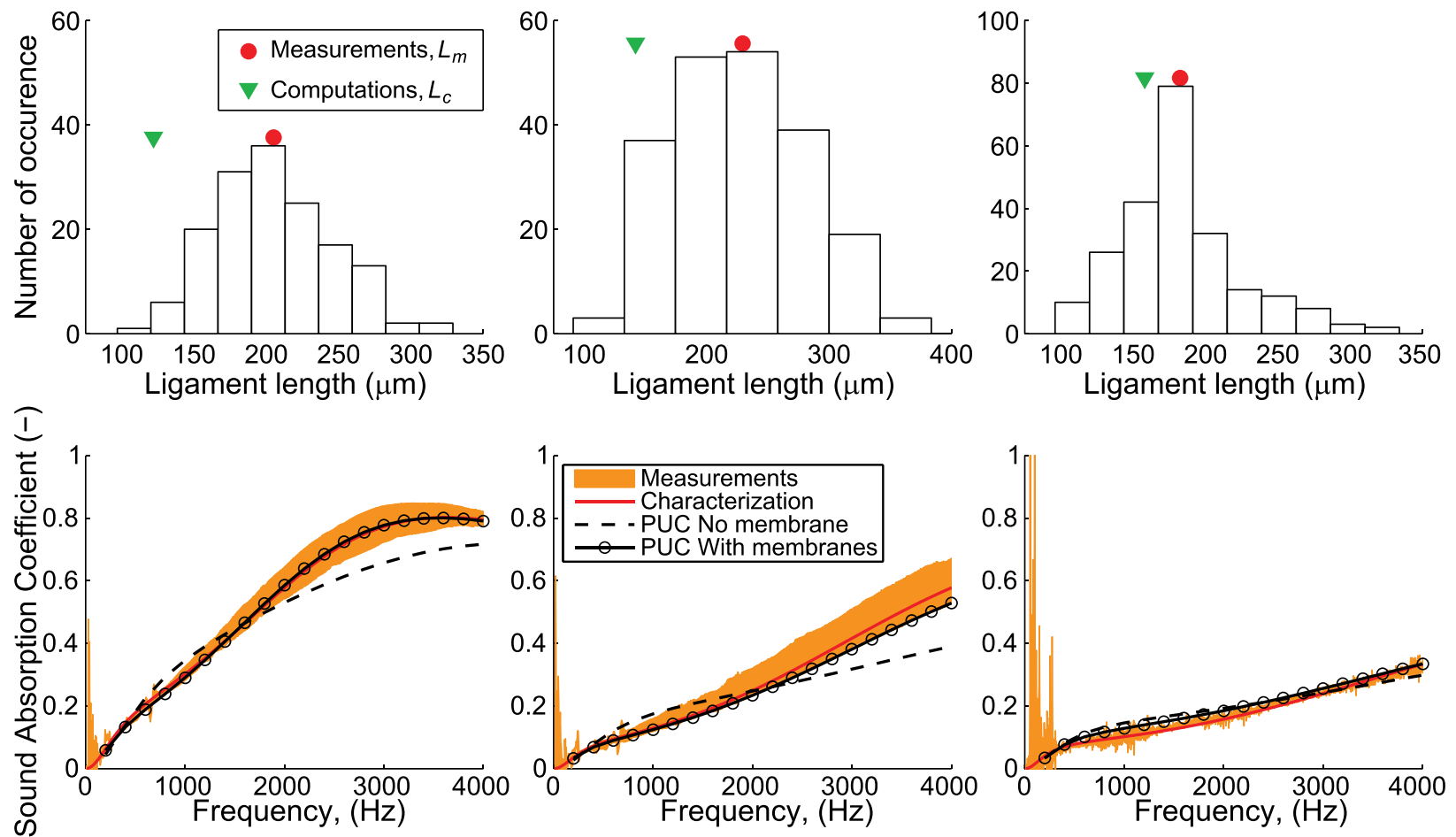

FIG. 1. Structure and sound-absorbing properties of three real polyurethane foam samples. (a) A scanning electron micrograph of a polyurethane foam sample illustrates a number of semi-open or even closed membranes, at the interconnection between pores which are filled with air, a visco-thermal fluid. The calibration bar corresponds to $1 \mathrm{~mm}$. Right: a schematic diagram depicts a single idealized periodic unit cell of polyurethane foam, without membranes at the fringe of its struts. (b) Ligament lengths distributions for three real foam samples (namely $\mathrm{R}_{1}, \mathrm{R}_{2}$, and $\mathrm{R}_{3}$ from left to right) together with superimposed average values of the experimental measurements $L_{m}$ (red circle) and the ligament length of the opened-cell solid foam structure with the same average permeability (green triangle) convey the impression of a missing microstructural ingredient in the periodic unit cell. This is confirmed by the computed sound absorption with the unit cell containing membranes (bottom). Computations were performed using first principles calculations of transport parameters, and Johnson $e^{2}$ al. ${ }^{4}$ combined with Lafarge $e t \mathrm{al}^{7}$ semi-phenomenological robust models. The thicknesses of the real polyurethane foam samples are $25 \mathrm{~mm}, 15 \mathrm{~mm}$, and $15 \mathrm{~mm}$, respectively from left to right.

created by an oscillating body in which the main visco-inertial and thermal dissipation processes occur are the viscous and thermal boundary layers. They, respectively, scale as $\sqrt{\nu / \omega}$ and $\sqrt{\nu^{\prime} / \omega}$, in which $\nu=\eta / \rho_{0}$ is the fluid's cinematic viscosity, $\nu^{\prime}=\kappa / \rho_{0} \mathbf{C}_{\mathbf{p}}$ is its thermal diffusivity, $\omega$ is the angular frequency of motion; and where $\eta$ is the fluid's dynamic viscosity, $\rho_{0}$ is its density at rest, $\kappa$ is its thermal conductivity, $\mathrm{C}_{\mathrm{p}}$ is the specific heat at constant pressure. For small perturbations, because the wavelength $\lambda$ of the incident compression wave greatly exceeds the typical pore size $D$ of the motionless porous media at audible frequencies, visco-inertial motions, and thermal conduction can be decoupled within a pore. On 
the other hand, the elastic behavior of the solid matrix may be subsequently incorporated as an additional pressure source term for the fluid flow. The viscous forces at low frequencies (Stokes flow), inertial forces at high frequencies (potential flow formally identical to electric conduction), and thermal conduction at low frequencies (similar to diffusion-controlled reactions) together determine all the transport parameters within a porous material.

Although ligament lengths distributions can be measured directly from microscopy analysis techniques, ${ }^{3}$ a quantitative appreciation of the critical size governing lowReynolds number hydrodynamics in real foam samples can be obtained from the associated permeability (Fig. 1). When a viscous fluid moves through a three-dimensional periodic local geometry model of opened-cell solid foam structure, the ligament length of the unit cell with the same average permeability is always lower or equal to the average length measured from microscopy analysis. One might therefore expect a significant local geometry feature for the real solid foam samples omitted in the model. Indeed, a careful observation of the real foam samples microstructure from micrographs may reveal residual solid films (at the periphery of the foam ligaments). Because we computed the permeability for three-dimensional periodic unit cells that lacked solid films, the corresponding ligament's length value is about a half of the typically reported foam from micrographs on non-fully reticulated real foam samples. We note that these solid film contents are also significant on other transport parameters related to inertial flow and diffusion-controlled reactions. The large differences between the transport parameters for an open cell and for a partially closed-cell of threedimensional local geometry models with identical viscous permeability reveal the striking role that solid films in real polymeric foam samples may play in the visco-inertial and thermal dissipation processes involved during acoustic wave propagation in polymeric foams at audible frequencies.

The first-principles calculation procedures of transport properties from a non-dimensional unit cell have been described. ${ }^{3}$ Although audible frequency sound waves propagating through air-saturated rigid porous media may be sensitive to a large range of local geometry characteristic sizes, their frequency-dependent macro-behavior is essentially determined by visco-inertial asymptotic transport parameters and their thermal counterparts. To estimate these transport parameters, we constructed a microstructure model of a solid foam unit-cell with air as a Newtonian viscous and thermally conducting filling liquid, preserving the scaling between the physical quantities of importance in the low-frequency asymptotic behavior (porosity and quasi-static viscous permeability). A simplified three-dimensional local geometry model of the opened-cell structure of polyurethane foam samples in which Stokes equations were solved was used to provide the initial characteristic ligament length estimate, $L_{c}$. A solid film was implemented at growing rates of $\Delta \delta=\delta_{\max } / 20$, while the unit-cell was rescaled to account for the film frictional forces, until ligament length $L$ is converged (Fig. 2). We estimated the transport parameters for the non-fully reticulated models of the polyurethane foam samples, which are in much better agreement than the ones computed without
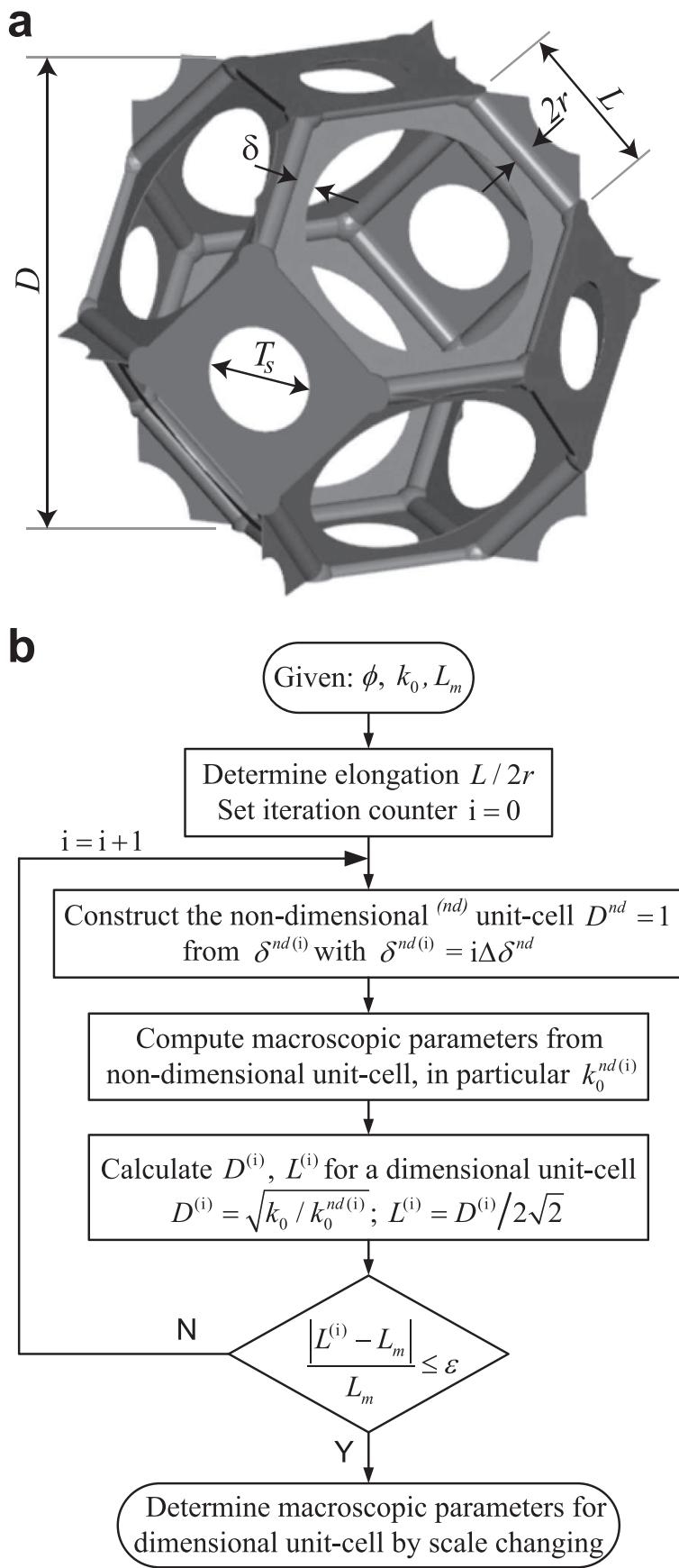

FIG. 2. Solid film implementation in a three-dimensional opened-cell model. (a) Illustration of a model with solid films implemented at the periphery of the struts, this feature of the microgeometry introduces a supplementary degree of freedom, from which a representative unit cell of the acoustical macro-behavior is found. The closure rate of the solid films $\delta / \delta_{\max }$ may progress from an opened-cell structure without any solid film $\left(\delta=0, \delta_{\max }=L / 2-r\right)$ to a relatively closed-cell structure when $\delta / \delta_{\max } \rightarrow$ 1, the throat size $T_{s}$ being the smallest interconnecting size between opened cells. (b) The first-principles calculation procedures of transport properties from a non-dimensional unit cell have been described. ${ }^{3}$ Here, this iterative procedure illustrates the importance of porosity $\phi$, permeability $k_{0}$; and average ligaments length $L_{m}$ measurements from which all the macroscopic parameters of interest for a real cellular solid with solid film content are computed without any adjustable constant. The reported macroscopic parameters are computed with a closure increment $\Delta \delta$ $=\delta_{\max } / 20$, and a relative difference between modeled and measured ligament lengths $\varepsilon=2 \%$. 
TABLE I. Comparison between measured, characterized, and computed macroscopic parameters for non-elongated unit-cells (with and without membranes). The porosity $\phi$ and viscous permeability $k_{0}$ are experimental data of the real foam sample, taken as input parameters for scaling the local geometry model, by solving Stokes equations in the periodic three-dimensional microstructure. This provides initial ligament lengths $L$ and thickness $2 r$ of the isotropic unit-cell. Then, the generalized hydraulic radius also known as the thermal characteristic length $\Lambda^{\prime}$ is deducted from integration over the scaled unit-cell. All the other macroscopic parameters are derived from first-principles calculations. ${ }^{2-4}$ Furthermore, an iterative strategy is used to increase the closure rate of membranes. With no adjustable parameters, the iteration counter is stopped when the ligament length of the membrane-based three-dimensional local geometry model is comparable with the measurements obtained from standard micrographs.

\begin{tabular}{|c|c|c|c|c|c|c|c|c|c|c|}
\hline Foams & Method & $\varphi(-)$ & $\Lambda^{\prime}(\mu \mathrm{m})$ & $k_{0}\left(\times 10^{-9} \mathrm{~m}^{2}\right)$ & $\Lambda(\mu \mathrm{m})$ & $\alpha_{\infty}(-)$ & $k_{0}^{\prime}\left(\times 10^{-9} \mathrm{~m}^{2}\right)$ & $L_{m}(\mu \mathrm{m})$ & $2 r(\mu \mathrm{m})$ & $\delta / \delta_{\max }(-)$ \\
\hline \multirow[t]{4}{*}{$\mathrm{R}_{1}$} & Measurements & $0.98 \pm 0.01$ & & $2.60 \pm 0.08$ & & & & $205 \pm 42$ & $31 \pm 7$ & \\
\hline & $\begin{array}{l}\text { Computations without } \\
\text { membranes }\end{array}$ & & $506 \pm 114$ & & $297 \pm 66$ & $1.02 \pm 0.01$ & $5.01 \pm 0.22$ & $123 \pm 13$ & $19 \pm 7$ & 0 \\
\hline & $\begin{array}{l}\text { Computations with } \\
\text { membranes }\end{array}$ & & $288 \pm 4$ & & $138 \pm 7$ & $1.17 \pm 0.02$ & $8.56 \pm 0.10$ & $207 \pm 4$ & $33 \pm 10$ & $0.40 \pm 0.04$ \\
\hline & Characterization & & $440 \pm 202$ & & $129 \pm 23$ & $1.12 \pm 0.2$ & $8.30 \pm 1.60$ & & & \\
\hline \multirow[t]{4}{*}{$\mathrm{R}_{2}$} & Measurements & $0.97 \pm 0.01$ & & $2.98 \pm 0.14$ & & & & $230 \pm 57$ & $36 \pm 8$ & \\
\hline & $\begin{array}{l}\text { Computations without } \\
\text { membranes }\end{array}$ & & $477 \pm 70$ & & $279 \pm 41$ & $1.02 \pm 0.01$ & $5.85 \pm 0.34$ & $141 \pm 12$ & $27 \pm 7$ & 0 \\
\hline & $\begin{array}{l}\text { Computations with } \\
\text { membranes }\end{array}$ & & $308 \pm 7$ & & $147 \pm 6$ & $1.18 \pm 0.02$ & $10.04 \pm 0.23$ & $229 \pm 1$ & $44 \pm 9$ & $0.40 \pm 0.04$ \\
\hline & Characterization & & $330 \pm 54$ & & $118 \pm 9$ & $1.13 \pm 0.04$ & $9.70 \pm 2.40$ & & & \\
\hline \multirow[t]{4}{*}{$\mathrm{R}_{3}$} & Measurements & $0.98 \pm 0.01$ & & $4.24 \pm 0.29$ & & & & $182 \pm 42$ & $30 \pm 6$ & \\
\hline & $\begin{array}{l}\text { Computations without } \\
\text { membranes }\end{array}$ & & $647 \pm 147$ & & $373 \pm 86$ & $1.01 \pm 0.01$ & $8.18 \pm 0.68$ & $157 \pm 19$ & $25 \pm 10$ & 0 \\
\hline & $\begin{array}{l}\text { Computations with } \\
\text { membranes }\end{array}$ & & $438 \pm 25$ & & $261 \pm 19$ & $1.04 \pm 0.01$ & $9.27 \pm 0.67$ & $178 \pm 6$ & $28 \pm 9$ & $0.05 \pm 0.05$ \\
\hline & Characterization & & $594 \pm 80$ & & $226 \pm 35$ & $1.06 \pm 0.02$ & $13.10 \pm 4.20$ & & & \\
\hline
\end{tabular}

solid films compared to standing waves tube measurements (Table I). This agreement demonstration confirmed that even a very small content of solid films plays an important role in the overall visco-inertial and thermal dissipation phenomena, indicating the importance of this particular local geometry feature in the identification of a representative unit-cell.

Viscous transport becomes dominant in the low frequency regime and inertial transport becomes dominant in the high-frequency regime of long wavelength acoustic wave propagation in rigid porous media. To quantify these transport properties as a function of cellular morphology, a finiteelement model in which we could manipulate the solid-film content of the cellular structure while explicitly representing the velocity field in and around the cellular morphology was used. The models have about 400000 degrees of freedom and rigorously resolve the liquid motion in the pore structure of non-fully reticulated polymeric foams as well as the temperature field outside the polymer films.

Due to the periodicity of the unit cell, $12 \times 1 / 4$ solid films are not lying along the faces of the polyhedron, contrary to the 14 remaining ones (Fig. 2). Here, the solid film thickness $t$ over ligament thickness $2 r$ was mainly set to a constant ratio, $t / 2 r \approx 1 / 20$. The porosities were therefore reduced to less than a percent when the solid films were implemented. The finite element model with solid films replicated the thermal length (mesh quality), when calculated with a geometrical model (analytical solution). Unlike the elastic properties in the deformable solid frame model for which the solid film thickness effect is strong, the film thickness in this instance does not affect the transport coefficients.

\section{RESULTS AND DISCUSSION}

First, we examined the model including only viscoinertial dissipation effects for non-elongated unit-cells through their corresponding transport parameters, the quasistatic viscous permeability $k_{0}$, the viscous characteristic length ${ }^{4} \Lambda$, and the tortuosity ${ }^{4} \alpha_{\infty}$. In Fig. 3, we plot the variation of the three asymptotic parameters $\Lambda, \alpha_{\infty}$, and $k_{0}^{\prime}$ for partially closed-cell models as a function of the closure rate of membranes $\delta / \delta_{\max }$. Since at $\delta / \delta_{\max } \rightarrow 1$ the throat tends to pinch off, $\alpha_{\infty}$ tends to diverge, and the values of $\Lambda$ tend to $T_{s}$. Adding to the open cell model, motionless solid films strongly increase $\alpha_{\infty}$ and reduce $\Lambda$. It is noted that specific values for the closure rate of membranes $\delta / \delta_{\max }$ may be chosen such that the ligament lengths of the non-fully reticulated unit-cells will match the average value of the experimental measurements performed on optical micrographs $\left(L=L_{m}\right)$.

Using a transfer function method for measuring the characteristic impedance and propagation constant ${ }^{6}$ of the real foam samples from a standing wave tube (the corresponding dynamic viscous and thermal permeability $k(\omega)$ and $k^{\prime}(\omega)$ were calculated) allowed us to calculate the dynamic density and dynamic bulk modulus of the materials, some quantities that could be directly compared with Johnson et ll $^{4}$ and Lafarge et al. ${ }^{7}$ models. Assuming porosity $\phi$ and quasi-static viscous permeability $k_{0}$ known from direct non-acoustical measurements, an experimental estimation of $\Lambda, \alpha_{\infty}$, and $k_{0}^{\prime}$ was obtained from the analytic inversion of the models. ${ }^{9}$ With no adjusted constant, the computed transport parameters corresponding to the aforementioned specific values of membrane closure rates are in good agreement 

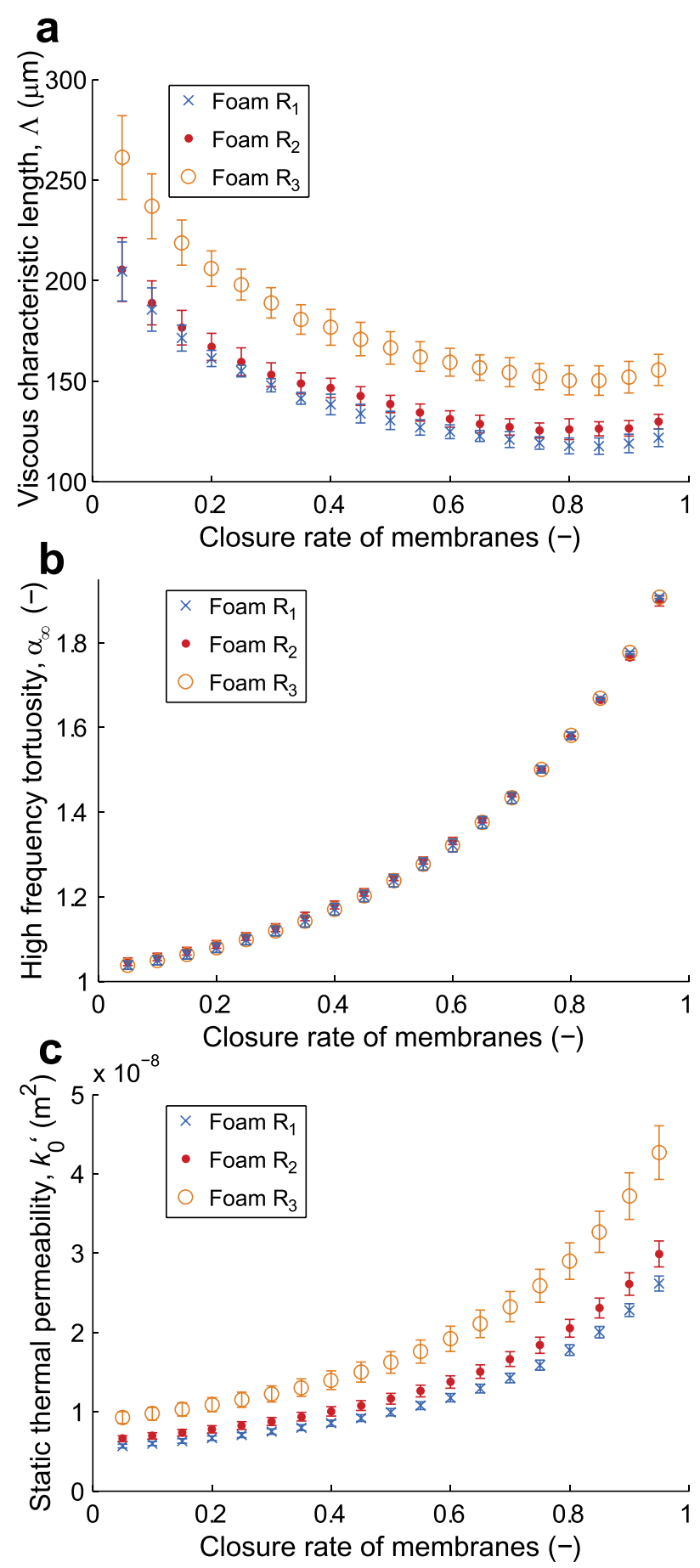

FIG. 3. Finite element analysis of transport properties in a cellular solid. The membrane closure rate dependence of the viscous characteristic length $\Lambda$ (a), the high frequency limit of the viscous tortuosity $\alpha_{\infty}(\mathrm{b})$, and the static thermal permeability $k_{0}^{\prime}$ (c) are obtained from the cellular solid model with three configurations of the measured porosity $\phi$ and permeability $k_{0}: \phi$ $=0.98 \pm 0.01$ and $k_{0}=2.60 \pm 0.08 \times 10^{-9} \mathrm{~m}^{2}$ (foam sample $\mathrm{R}_{1}$, blue crosses), $\phi=0.97 \pm 0.01$ and $k_{0}=2.98 \pm 0.14 \times 10^{-9} \mathrm{~m}^{2}$ (foam sample $\mathrm{R}_{2}$, red circles), $\phi=0.98 \pm 0.01$ and $k_{0}=4.24 \pm 0.29 \times 10^{-9} \mathrm{~m}^{2}$ (foam sample $\mathrm{R}_{3}$, orange circles). The error bars were calculated by standard deviations when taking into account all possible cellular configurations associated with porosity and permeability experimental uncertainties.

with experimental characterization data. Adding to the threedimensional local geometry model a closure rate of membranes, rather than no solid films, introduces an accurate description of the throat size area, which is critical to the determination of $\Lambda$ and $\alpha_{\infty}$. Consequently, this provides us with a cellular morphologically based method for the identification of the second critical linkage dominating, at highfrequencies, the dynamic viscous permeability (from the knowledge of the first critical linkage dominating, at lower frequencies, the dynamic viscous permeability). Let $k_{c}$ and $\alpha_{c}$ be the two scaling parameters ${ }^{2}$ for the real and non-fully reticulated foam samples, $k(\omega)$ is thus expected to be entirely determined by simple measurements of $\phi, k_{0}$, and $L_{m}$ (since $k_{c}=k_{0}$ and $\alpha_{\mathrm{c}}$ derives from our cellular morphologically based method).

Next, we considered more thoroughly the evolution of the thermal permeability $k_{0}^{\prime}=1 / \Gamma$ as a function of the closure rate of solid membranes $\delta / \delta_{\max }$, a quantity related to the pore space diffusion. ${ }^{8}$ In this regard, it is not clear whether the above quantity provides an accurate description of the pore geometry. Indeed, contrary to $k_{0}, \Lambda$ and $\alpha_{\infty} ; k_{0}{ }^{\prime}$ is not directly related to connectivity of the pore space. If the links between the pores were gradually eliminated by solid films, the permeability would rapidly approach zero while the value of $k_{0}{ }^{\prime}$ would not be greatly affected. ${ }^{10}$ Because pore sizes increase with membrane closure rates whereas throat sizes decrease for a given non-zero static viscous permeability $k_{0}$, diffusion-controlled reactions progressively become very sensitive to the wetted surface area of solid films. As the pore links subside, the $k_{0}^{\prime}$ coefficient provides the most accurate probe to solid film content of the real porous structure (Fig. 3). It is helpful here to restate that the diffusing particles corresponding to a scalar field move randomly and explore the three-dimensional porous space without any privileged directions. This is to be contrasted with the visco-inertial transport parameters $k_{0}, \alpha_{\infty}$, and $\Lambda$, which relate to vector fields and favored directions. Therefore, for connected pores, the $k_{0}^{\prime}$ coefficient gives a better estimate of the membrane closure rate for a cellular solid containing solid films. This remark is corroborated by the periodic homogenization and consistent estimates of transport parameters through polyhedron packings modeling study (Sec. V D). ${ }^{11}$ It should be noted that Ref. 12 give an evaluation for $k_{0}^{\prime}$ based on acoustic experiments that, when combined with Fig. 3, would give an estimate of the membrane closure rate $\delta / \delta_{\max }$. Predictions of $\delta / \delta_{\max }$ and $k_{0}{ }^{\prime}$ using direct measurements on two-dimensional or threedimensional images are not yet established, however, and is thus beyond the scope of this paper.

In conclusion, because all parts of the motionless disordered network of struts or plates forming a real cellular solid with the air as filling phase do not play the same role in the overall frequency-dependent response function, with a long wavelength acoustic signature governed essentially from the low and high frequency asymptotic regimes, most microstructural details inside the real foam samples are inferred from simple measurements of open porosity, permeability, and ligament lengths. Although solid films might be thought to be non-significant details, the cellular solids microstructure actually involves membranes in visco-inertial and thermal energy dissipation, making it critical for the multi-scale modeling process to design solid foams with tailored transport properties. The enhanced fluid-structure interface due to 
solid films even suggests static thermal permeability as an asset by using it as a simple means of characterizing the closed pore content of real porous media.

\section{ACKNOWLEDGMENTS}

We thank F. Chevillotte from Matelys for programming the fluid finite-element model under ScalingCell (http:// www.matelys.com/) and using FreeFEM ++ developed at Laboratoire Jacques-Louis Lions in the Paris VI University (http://www.freefem.org/); F.-X. Bécot and L. Jaouen for discussions about experimental characterization data through impedance tube measurements; L. Gautron and R. Combes for help with measuring ligament lengths and thicknesses through optical and electron micrograph analysis; J.-F. Rondeau, R. Panneton, A. Duval, and G. Bonnet for helpful discussions during the course of this work; and M.-H. Alexandre for assistance in improving the English quality of this paper. This work was part of a project supported by ANRT and Faurecia Interior Systems Acoustic TechCenter under convention CIFRE No. 748/2009.

\footnotetext{
${ }^{1}$ A. J. Katz and A. H. Thompson, "Quantitative prediction of permeability in porous rock,” Phys. Rev. B 34, 8179 (1986).

${ }^{2}$ P. Sheng and M.-Y. Zhou, "Dynamic permeability in porous media," Phys. Rev. Lett. 61, 1591 (1988).

${ }^{3}$ C. Perrot, F. Chevillotte, M. T. Hoang, G. Bonnet, F.-X. Bécot, L. Gautron, and A. Duval, "Microstructure, transport, and acoustic properties of open-cell foam samples: Experiments and three-dimensional numerical simulations," J. Appl. Phys. 111, 014911 (2012).
}

${ }^{4}$ D. L. Johnson, J. Koplik, and R. Dashen, “Theory of dynamic permeability and tortuosity in fluid-saturated porous media," J. Fluid Mech. 176, 379 (1987).

${ }^{5}$ G. Kirchhoff, "Über den Einfluss der Wärmeleitung in einem Gase auf die Schallbewegung," Ann. Phys. Chem. 134, 177 (1868) ["On the influence of heat conduction in a gas on sound propagation," in Physical Acoustics, edited by R. B. Lindsay (Hutchison \& Ross, Dowden, 1974)]; see also W. Strutt (Lord Rayleigh), Theory of Sound, 2nd ed. (Dover, New York, 1945) Vol. II, Sec. 348; and C. Zwikker and C. W. Kosten, Sound Absorbing Materials (Elsevier, New York, 1949), Chapter II.

${ }^{6}$ H. Utsuno, T. Tanaka, T. Fujikawa, and A. F. Seybert, "Transfer function method for measuring characteristic impedance and propagation constant of porous materials," J. Acoust. Soc. Am. 86, 637 (1989).

${ }^{7}$ D. Lafarge, P. Lemarinier, J. F. Allard, and V. Tarnow, "Dynamic compressibility of air in porous structures at audible frequencies," J. Acoust. Soc. Am. 102, 1995 (1997).

${ }^{8} \mathrm{~J}$. Rubinstein and S. Torquato, "Diffusion-controlled reactions: Mathematical formulation, variational principles, and rigorous bounds," J. Chem. Phys. 88, 6372 (1988).

${ }^{9}$ R. Panneton and X. Olny, "Acoustical determination of the parameters governing viscous dissipation in porous media," J. Acoust. Soc. Am. 119, 2027 (2006); X. Olny and R. Panneton, "Acoustical determination of the parameters governing thermal dissipation in porous media," J. Acoust. Soc. Am. 123, 814 (2008).

${ }^{10}$ L. M. Schwartz, N. Martys, D. P. Bentz, E. J. Garboczi, and S. Torquato, "Cross-property relations and permeability estimation in model porous media," Phys. Rev. E 48, 4584 (1993).

${ }^{11}$ C. Boutin and C. Geindreau, "Periodic homogenization and consistent estimates of transport parameters through sphere and polyhedron packings in the whole porosity range," Phys. Rev. E 82, 036313 (2010).

${ }^{12}$ A. Debray, J.-F. Allard, W. Lauriks, and L. Kelders, "Acoustical measurements of the trapping constant of porous materials," Rev. Sci. Instrum. 68, 4462 (1997); M. Sadouki, M. Fellah, Z. E. A. Fellah, E. Ogam, N. Sebaa, F. G. Mitri, and C. Depollier, "Measuring static thermal permeability and inertial factor of rigid porous materials," J. Acoust. Soc. Am. 130, 2627 (2011). 